\title{
ESTUDO SOBRE O CAIMENTO DE PRODUTOS CONFECCIONADOS COM MODELAGEM IDÊNTICA E MATERIAIS DIFERENTES
}

Patricia de Mello Souza

Universidade Estadual de Londrina

patriciademellosouza@gmail.com

Carolina Mendes Pereira Roberto

Universidade Estadual de Londrina

caru.mendes@hotmail.com

Daniele Caroline Antunes

Universidade Estadual de Londrina

daniele.caroline.antunes@gmail.com

Resumo: $O$ presente trabalho visou o estudo de materiais têxteis e modelagem, tendo como objetivo investigar o caimento de produtos elaborados a partir de modelagens idênticas, porém com tecidos diferentes. Investigou-se as características das superfícies têxteis usadas para a confecção de produtos e avaliou-se subjetivamente por meio de percepção visual e observação as alterações de caimento. Segundo Souza (2013), o caimento é um fenômeno produzido pela gravidade em uma superfície têxtil presa em um único ponto. Alguns fatores que influenciam no comportamento do caimento são o ponto de sustentação, ponto de tensão, ponto de apoio, inércia, ar e fio do tecido, afirmam Costa e Silva (2016). De acordo com Souza e Menezes (2014), estes materiais têxteis se tornam elementos importantes para a construção, pois ampliam as possibilidades de reestruturação do corpo, configurando as mais diversas silhuetas. Esta importância do tecido está vinculada às potencialidades técnicas que determinam distintas aplicações e resultados. Seivewright (2009) ressalta a relevância do conhecimento sobre os materiais e suas características. Estes atributos, de acordo com Aldrich (2013), são: peso, espessura, distorção, drapeabilidade e elasticidade. Estes devem ser analisados pois exercem grande influência no comportamento e aspecto visual dos produtos, alterando sua estrutura. Com base nestes estudos, elaborou-se produtos de moda em distintos materiais a partir de uma mesma modelagem a fim de analisar as possíveis silhuetas obtidas pelo uso de materiais com características diferentes. Os modelos dos produtos foram primeiramente desenvolvidos a partir de técnicas de modelagem tridimensional em manequins de escala 1:2 como suporte. Foram também elaboradas tabelas comparativas com todas as informações dos materiais utilizados, bem como as fotos dos produtos, para serem investigadas e avaliadas as diferenciações entre eles. Segundo Mariano (2011), a modelagem tridimensional permite trabalhar o tecido diretamente sobre 
um manequim e possibilita controlar as relações de ajuste e afastamento do tecido com base no formato corporal, bem como visualizar imediatamente o caimento do tecido. Após os produtos serem desenvolvidos tridimensionalmente, eles foram elaborados em modelagens bidimensionais, analisando-se proporções e medidas necessárias para a reprodução do modelo em tecidos diferentes. Alguns produtos foram cortados no fio reto e outros no viés com a intenção de avaliar a configuração e o caimento. De acordo com os resultados obtidos foi possível visualizar diferenças das silhuetas a partir dos modelos reproduzidos. Foi observado que os modelos cortados no viés possuem maior proximidade ao corpo vestido, pois a drapeabilidade é menor, apresentando uma silhueta mais perceptível e definida. Não somente as características do tecido influenciam na configuração do produto, mas também na forma como o molde é posicionado na superfície têxtil para ser cortado, criando assim, possibilidades de silhuetas de um mesmo produto.

Palavras-chave: Design de Moda, modelagem tridimensional, materiais têxteis, caimento.

\section{REFERÊNCIAS}

ALDRICH, Winifred. Tejido, forma y patronaje plano. Barcelona: GG Moda, 2010SOUZA, Patrícia de Mello. Estratégias de construção para estruturas têxteis vestíveis. 2013. Tese (Doutorado em Design) - Faculdade de Arquitetura, Artes e Comunicação, Universidade Estadual Paulista, Bauru, 2013.

COSTA, Andrea Fernanda de Santana; SILVA, Tamires Meire Lira. 0 comportamento de queda do fio e o caimento do tecido: duas combinações, um bom resultado no vestuário. Disponível em: < http://coloquiomoda.com.br/anais/anais/7-Coloquio-deModa_2011/GT13/Comunicacao-

Oral/CO_895910_comportamento_de_queda_do_fio_e_o_caimento_do_tecido_duas _combinacoes_um_bom_resultado_no_vestuario_.pdf>. Acesso em: 22 abr. 2016.

MARIANO, Maria Luiza Veloso. Da construção à desconstrução: a modelagem como recurso criativo no Design de Moda. São Paulo, 2011. Dissertação de Mestrado.

Universidade Anhembi Morumbi.

SEIVEWRIGHT, Simon. Fundamentos de Design : Pesquisa e design . Porto Alegre: Bookman , 2009. p. 176. Tradução: Edson Furmankiewicz.

SPAINE, Patrícia Aparecida de Almeida; BRITO, Débora Mizubuti; e MENEZES, Marizilda dos Santos. A Modelagem Híbrida no design do vestuário $2^{\circ} \mathrm{CIMODE}, 2014$, P. 1838.

SOUZA, Patrícia de Mello; MENEZES, Marizilda dos Santos. RECURSOS DE

CONSTRUÇÃO PARA ESTRUTURAS TÊXTEIS VESTíVEIS. In: COLÓQUIO DE MODA, 10., 2014, Caxias do Sul. Anais... . Caxias do Sul: Colóquio, 2014. p. 1 - 13. 